\title{
TRATAMENTO POR ÁGUA QUENTE NA QUALIDADE DE MAÇÃS 'FUJI', INOCULADAS ARTIFICIALMENTE COM Botryosphaeria dothidea, EM ARMAZENAMENTO REFRIGERADO ${ }^{1}$
}

\author{
HOT WATER TREATMENTS ON FRUIT QUALITY OF'FUJI' APPLES ARTIFICIALLY \\ INOCULATED WITH Botryosphaeria dothidea, IN REFRIGERATED STORAGE
}

\author{
Rosangela Lunardi $^{2}$ Eduardo Seibert ${ }^{3}$ Ernani Pezzi $^{4}$ Renar João Bender ${ }^{5}$
}

RESUMO

\begin{abstract}
O objetivo deste trabalho foi avaliar a ocorrência de perdas físico-químicas em maçãs cultivar Fuji, previamente inoculadas com o fungo causador da podridão branca (Botryosphaeria dothidea (Moug.:Fr.) Ces. \& De Not), em armazenamento refrigerado $(A R)$, à temperatura de $0-1^{\circ} \mathrm{C}$. Os tratamentos foram combinações de 3 períodos $(1,2$ e 3 minutos) $e$ 3 temperaturas da água de imersão (47, 49 e $52^{\circ} \mathrm{C}$ ). As maçãs foram avaliadas após 1, 3 e 5 meses em AR e após 7 dias em temperatura ambiente. Ao final de cada período de armazenagem, as maçãs foram avaliadas para as seguintes variáveis: firmeza de polpa, sólidos solúveis totais (SST), acidez. titulável e perda de peso. O tratamento térmico reduziu os teores de acidez titulável, aumentou os teores de SST, e pouco influenciou na firmeza de polpa e perda de peso.
\end{abstract}

Palavras-chave: tratamento térmico, Malus domestica Borkh., podridão branca.

\section{SUMMARY}

The objective of the present study was to evaluate the effects of heat treatments on quality parameters of Fuji' apples. Apples were immersed for either one, two or three minutes in water at 47,49 or $52^{\circ} \mathrm{C}$. Before the heat treatments the apples had been artificially inoculated with the fungus Botryosphaeria dothidea (Moug.: Fr) Ces. \& De Not. After the heat treatments, the apples were stored in refrigerated air storage at $0-1{ }^{\circ} \mathrm{C}$ for one, three or five months plus seven days at room temperature. At the end of each storage period, apples were evaluated for flesh firmness, total soluble solids (TSS), titratable acidity and weight loss. The heat treatments resulted in reduced titratable acidity, increased TSS contents and had little influence on flesh firmness and weight loss.

Key words: heat treatment, Malus domestica Borkh., white rot.

\section{INTRODUÇÃO}

O método mais utilizado para o controle pós-colheita de podridões é o da aplicação de produtos químicos. Porém, devido às grandes restrições ao uso de agroquímicos, principalmente em período próximo à colheita, métodos físicos têm se configurado em alternativas promissoras. Dentre estes métodos, está o uso de calor, que pode ser aplicado de várias formas: imersão ou aspersão de água quente, vapor quente, ar seco quente, radiação infravermelha e radiação por microondas (COUEY, 1989), e radiação ultravioleta (D`HALLEWIN et al., 1994).

O uso de calor tem sido estudado para um grande número de espécies frutíferas, incluindo a maçã (KLEIN et al., 1997; LURIE et al., 1998; CONWAY et al, 1999). Conforme KLEIN \& LURIE (1990), o tratamento térmico aumentou a

\footnotetext{
${ }^{1}$ Parte da dissertação desenvolvida pelo primeiro autor para obtenção do grau de Mestre em Fitotecnia, Universidade Federal do Rio Grande do Sul (UFRGS).

${ }^{2}$ Engenheiro Agrônomo Mestre, doutorando em Agronomia, Universidade Federal de Pelotas (UFPel). E-mail: lunardi@ufpel.tche.br.

${ }^{3}$ Engenheiro Agrônomo Mestre, doutorando em Fitotecnia, UFRGS.

${ }^{4}$ Engenheiro Agrônomo, laboratorista, Departamento de Horticultura e Silvicultura, UFRGS.

${ }^{5}$ Engenheiro Agrônomo, Doutor, Professor do Departamento de Horticultura e Silvicultura, Faculdade de Agronomia, UFRGS. Av. Bento Gonçalves, 7712, 91501-970, Porto Alegre, RS. E-mail: rjbe@ vortex.ufrgs.br. Autor para correspondência.
} 
armazenabilidade das maçãs das cultivares Anna e Granny Smith. Nestas cultivares, a perda de firmeza da polpa após o armazenamento foi significativamente reduzida pelo pré-aquecimento por 4 dias a $38^{\circ} \mathrm{C}$. Este efeito benéfico na manutenção da firmeza dos tecidos foi confirmada em trabalhos de BEN-SHALOM et al. (1996) e LURIE et al. (1998). Os mecanismos envolvidos na manutenção da firmeza da polpa não estão bem claros, mas CONWAY et al. (1994) atribuíram o efeito à ausência ou à baixa atividade de enzimas que atuam na degradação da parede celular, baseados também nas determinações de conteúdo de poliuronídeos, pectinas solúveis e insolúveis em água e pectatos de cálcio de LURIE \& KLEIN (1992) maiores em frutos tratados do que naqueles não tratados.

Os efeitos benéficos de combinações de período de tratamento e temperatura do meio nos tratamentos de calor, de acordo com NYANJAGE $\boldsymbol{e t}$ al. (1998), não podem ser generalizados. Segundo os autores, há interações decisivas, como efeito de cultivares, fatores pré-colheita e condições de armazenamento, que influenciam a eficiência dos tratamentos.

Considerando que maçãs têm apresentado, nos últimos anos, problemas crescentes em pós-colheita devidos a podridões de origem latente (BONETI \& KATSURAYAMA, 1998) e baseado nas conclusões de NYANJAGE $\boldsymbol{e t} \boldsymbol{a l}$. (1998), foi realizado o presente trabalho com maçãs da cv. Fuji. O objetivo foi avaliar a ocorrência de perdas físico-químicas em maçãs inoculadas artificialmente com o fungo Botryosphaeria dothidea em armazenamento refrigerado por até 5 meses.

\section{MATERIAL E MÉTODOS}

O experimento foi conduzido nos laboratórios do Departamento de Horticultura e Silvicultura da Faculdade de Agronomia da Universidade Federal do Rio Grande do Sul (UFRGS) e na unidade frigorífica da Empresa Mercochem de Caxias do Sul, RS. As maçãs da cv. Fuji foram colhidas de pomares da Mercochem em 25 de maio de 1999 e colocadas em resfriamento em câmara fria a $0^{\circ} \mathrm{C}$. Um dia após a colheita, as maçãs foram selecionados para defeitos e tamanho. No dia da instalação, analisou-se uma amostra para os parâmetros de maturação: firmeza de polpa de $70,4 \mathrm{~N}$; sólidos solúveis totais (SST) de $14,0^{\circ}$ Brix e acidez titulável de $1,75 \mathrm{Cmol} . \mathrm{L}^{-1}$.

No laboratório, as maçãs foram inoculadas com o fungo Botryosphaeria dothidea (Moug.:Fr) Ces. \& De Not, agente causal da podridão branca, aplicando-se discos de cerca de $4 \mathrm{~mm}$ de diâmetro, retirados aleatoriamente da colônia, em placas de Petri com cultura do fungo. O agente causal foi previamente incubado em meio BDA (batata + dextrose + ágar), contendo o antibiótico estreptomicina $\left(100 \mu \mathrm{g} \cdot \mathrm{m} \ell^{-1}\right)$. A região equatorial das maçãs, na qual foi feita a inoculação, foi lesionada superficialmente com agulhas para um tamanho de $2 \mathrm{~mm}$ de diâmetro. Para proteger a parte inoculada, as maçãs foram envolvidas por uma tira de polietileno ao redor do fruto.

As maçãs permaneceram em sacos plásticos, conforme recomendação de DHINGRA \& SINCLAIR (1995), por um período de 40 horas, em uma estufa incubadora de BOD, à temperatura de $28^{\circ} \mathrm{C}$, para garantir a penetração do patógeno. Após este período, as maçãs foram submetidas aos tratamentos térmicos.

Os tratamentos compreenderam a imersão das maçãs em água quente, com exceção da testemunha, que apenas sofreu a inoculação. Utilizaram-se três períodos de imersão em água quente: 1, 2 ou 3 minutos, combinados com três temperaturas: 47,49 ou $52^{\circ} \mathrm{C}$.

A temperatura da água e de três regiões da polpa da maçã foi monitorada utilizando-se termopares confeccionados com fios de cobre e constantan, conectados a um microvoltímetro. As leituras de temperatura foram feitas em três profundidades de polpa: $0,5 \mathrm{~cm}, 1,5 \mathrm{~cm}$ e a $2,5 \mathrm{~cm}$ da superfície. As leituras foram feitas a cada dez segundos, durante o período de tratamento em imersão em água, e durante os quatro minutos seguintes à retirada das maçãs dos tratamentos de imersão. A partir deste tempo, a temperatura da polpa ainda foi monitorada por mais 26 minutos, com leituras a cada minuto, totalizando, pelo menos, 31 minutos de acompanhamento da temperatura de polpa.

As leituras no microvoltímetro foram convertidas para ${ }^{\circ} \mathrm{C}$, segundo a fórmula adaptada pelo Departamento de Plantas Forrageiras e Agrometeorologia da Faculdade de Agronomia da Universidade Federal do Rio Grande do Sul: ${ }^{\circ} \mathrm{C}=$ $0,288+0,024835 * \mu \mathrm{V}$; onde $\mu \mathrm{V}=$ leitura no microvoltímetro.

Após a aplicação dos tratamentos térmicos, as maçãs foram armazenadas em ar refrigerado (AR), em temperatura de $0-1{ }^{\circ} \mathrm{C}$ e umidade relativa do ar entre 85 e $90 \%$, na unidade frigorífica Mercochem em Caxias do Sul, RS.

As maçãs foram avaliadas após um três e cinco meses de armazenamento em ar refrigerado mais sete dias de exposição à temperatura ambiente, simulando o período de comercialização. Os parâmetros avaliados foram: firmeza de polpa $(\mathrm{N})$, determinada através do uso de penetrômetro manual, com ponteira de $11 \mathrm{~mm}$ de diâmetro, após a remoção 
da casca, em dois lados opostos da região equatorial do fruto; sólidos solúveis totais (SST) ( ${ }^{\circ}$ Brix), determinados por refratômetro de mesa; acidez titulável $\left(\mathrm{Cmol} \cdot \ell^{-1}\right)$, determinada pela titulação de $10 \mathrm{ml}$ de suco diluídos em $90 \mathrm{ml}$ de água destilada, com uma solução de $\mathrm{NaOH} 0,1 \mathrm{~N}$ até $\mathrm{pH} 8,1$; e perda de peso (\%), determinada pela diferença de peso dos frutos entre a instalação do experimento e após o armazenamento.

O experimento foi conduzido segundo o delineamento experimental inteiramente casualizado, com três repetições por tratamento, em esquema fatorial (combinações de temperaturas $\mathrm{x}$ tempos de imersão), e a unidade experimental composta por cinco frutos. Os dados foram submetidos à análise de variância, através do programa estatístico Sanest, e as médias comparadas estatisticamente pela regressão polinomial em nível de $5 \%$ de probabilidade de erro.

\section{RESULTADOS E DISCUSSÃO}

As diferenças entre firmeza de polpa das maçãs só foram significativas após cinco meses em AR mais sete dias em temperatura ambiente. Estas diferenças foram resultantes do efeito das temperaturas independentemente do período de exposição (Figura 1). O aumento dos níveis de firmeza de polpa das maçãs tratadas pela temperatura mais elevada de $52^{\circ} \mathrm{C}$ em comparação ao tratamento com $49^{\circ} \mathrm{C}$ pode ser devido à inativação, apenas com a temperatura mais elevada, de enzimas que atuam na despolimerização das pectinas da parede celular.

Com cinco meses em AR a integridade das maçãs da cv. Fuji neste experimento estava bastante comprometida pelo aumento da podridão branca quando foram feitas as análises das variáveis de maturação e qualidade. Mesmo fazendo o teste penetrométrico em áreas sadias das maçãs, os resultados podem ter influência do ataque do patógeno. Nas avaliações do primeiro e terceiro mês de AR não foram detectadas diferenças na firmeza de polpa das maçãs dos vários tratamentos.

Não houve também diferenças de firmeza de polpa entre as maçãs que foram submetidas aos tratamentos térmicos e o tratamento testemunha (Figura 1), contrariando resultados de CONWAY et al. (1994) e LURIE et al. (1998). Estes autores observaram que os frutos aquecidos apresentavam-se mais firmes que aqueles que não sofreram tratamento térmico, possivelmente por inativação dos complexos enzimáticos da parede celular.

O teor de SST foi a variável mais influenciada pelo tratamento térmico. No entanto, esta variável não é muito indicada para avaliações de perdas de qualidade, pois é bastante instável, com variações de ano para ano (BENDER, 1986). Na avaliação do primeiro mês em AR, observou-se que os SST diminuíram com o aumento do período de exposição às temperaturas altas dos tratamentos, independentemente da temperatura da água de imersão. Aos três meses em AR, houve uma interação entre tempo de tratamento e temperatura da água (Figura 2A).

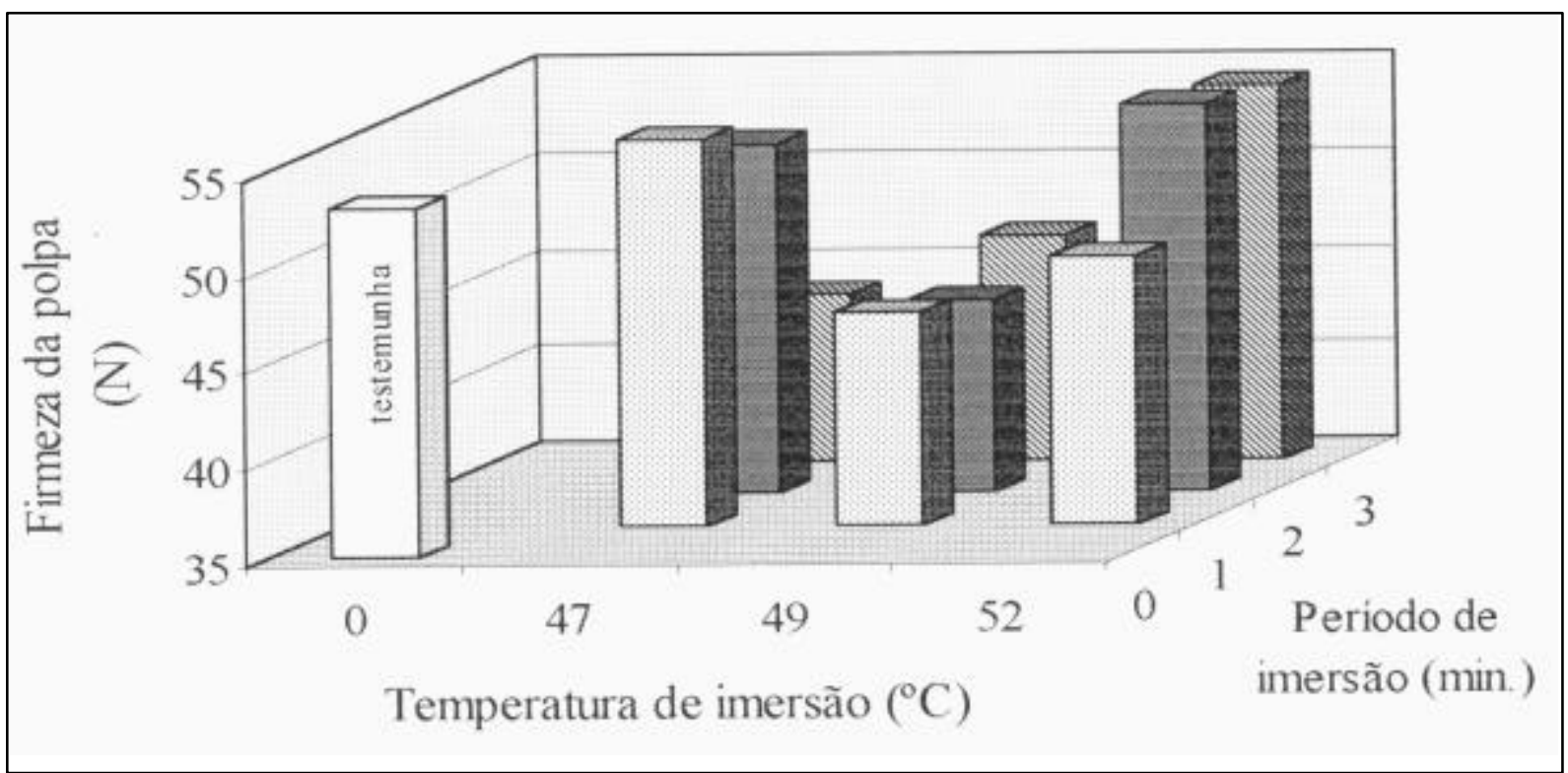

Figura 1 - Firmeza da polpa de maçãs cv. Fuji, inoculadas com Botryosphaeria dothidea, submetidas ao tratamento térmico com imersão em água quente, avaliadas após cinco meses em armazenamento refrigerado a $0^{\circ} \mathrm{C}$ mais sete dias em temperatura ambiente. 


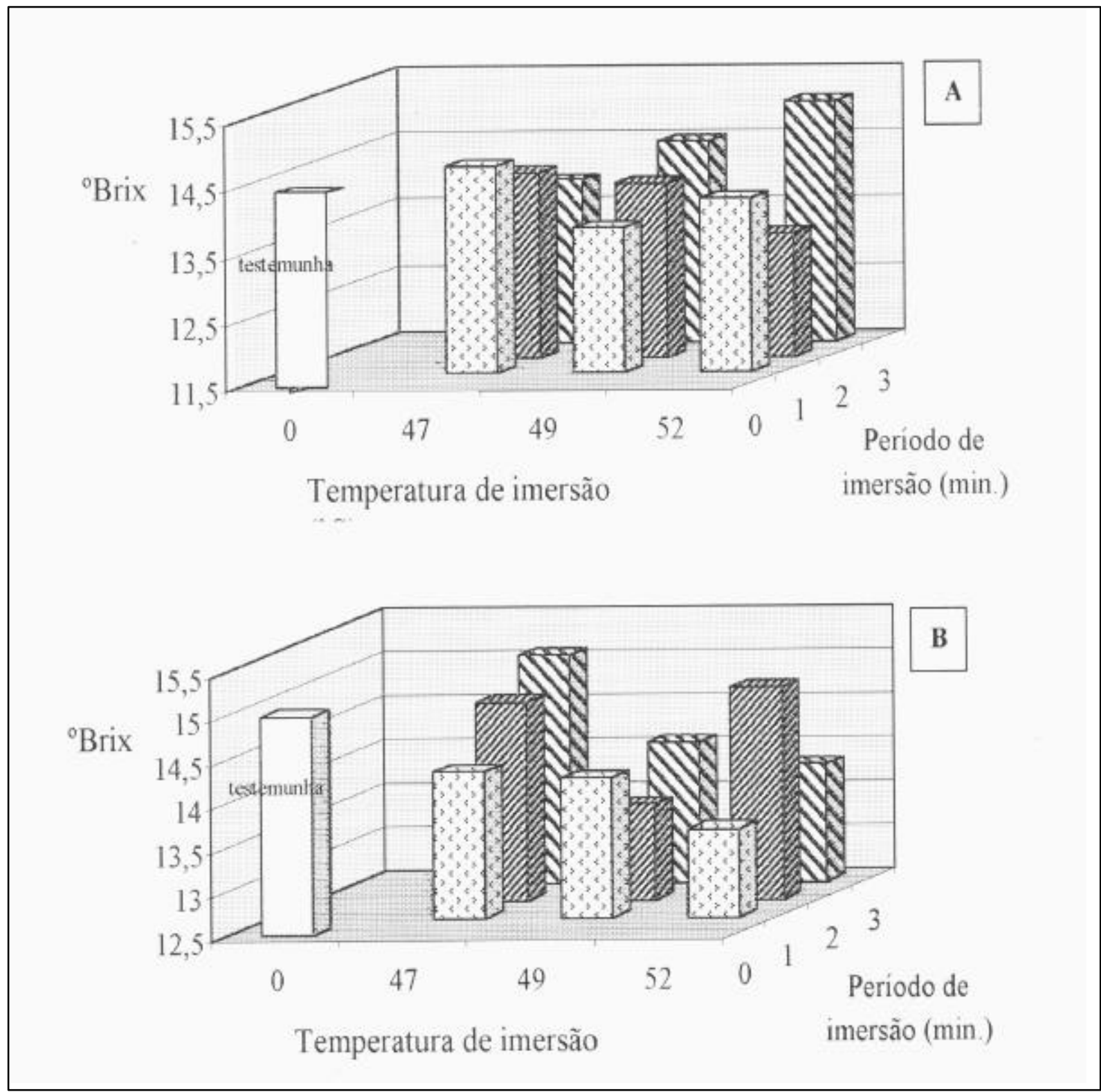

Figura 2 - Teores de sólidos solúveis totais de maçãs cv. Fuji, inoculadas com Botryosphaeria dothidea, submetidas ao tratamento térmico com imersão em água quente, avaliadas após três meses em armazenamento refrigerado a $0^{\circ} \mathrm{C}(\mathrm{A})$ ou cinco meses em armazenamento refrigerado a $0^{\circ} \mathrm{C}$ mais 7 dias em temperatura ambiente (B).

O decréscimo dos SST se deve ao consumo de substratos pelo metabolismo respiratório, após uma acentuada degradação dos ácidos orgânicos (BRACKMANN, 1990). Já o aumento dos SST decorre, provavelmente, da hidrólise de algum amido ainda presente nos tecidos.

Após cinco meses em AR, os SST variaram somente após sete dias em temperatura ambiente. As maçãs que receberam tratamento com água quente apresentaram teores de SST menores que as maçãs do tratamento testemunha. KLEIN \& LURIE (1990), no entanto, determinaram teores de
SST mais elevados nos frutos aquecidos em comparação ao tratamento testemunha.

No presente experimento, as maçãs submetidas ao tratamento térmico apresentaram diferença significativa $\left(y=0,09 x^{2}-8,64 x+230,6\right.$; $\left.\mathrm{r}^{2}=1,00\right)$ para temperaturas de tratamento, independentemente do tempo de exposição à temperatura elevada (Figura 2B), indicando que houve decréscimo dos SST quando se elevou a temperatura de imersão de $47^{\circ} \mathrm{C}$ para $49^{\circ} \mathrm{C}$, o que pode ser resultante do aumento da atividade metabólica em condição de estresse mais 


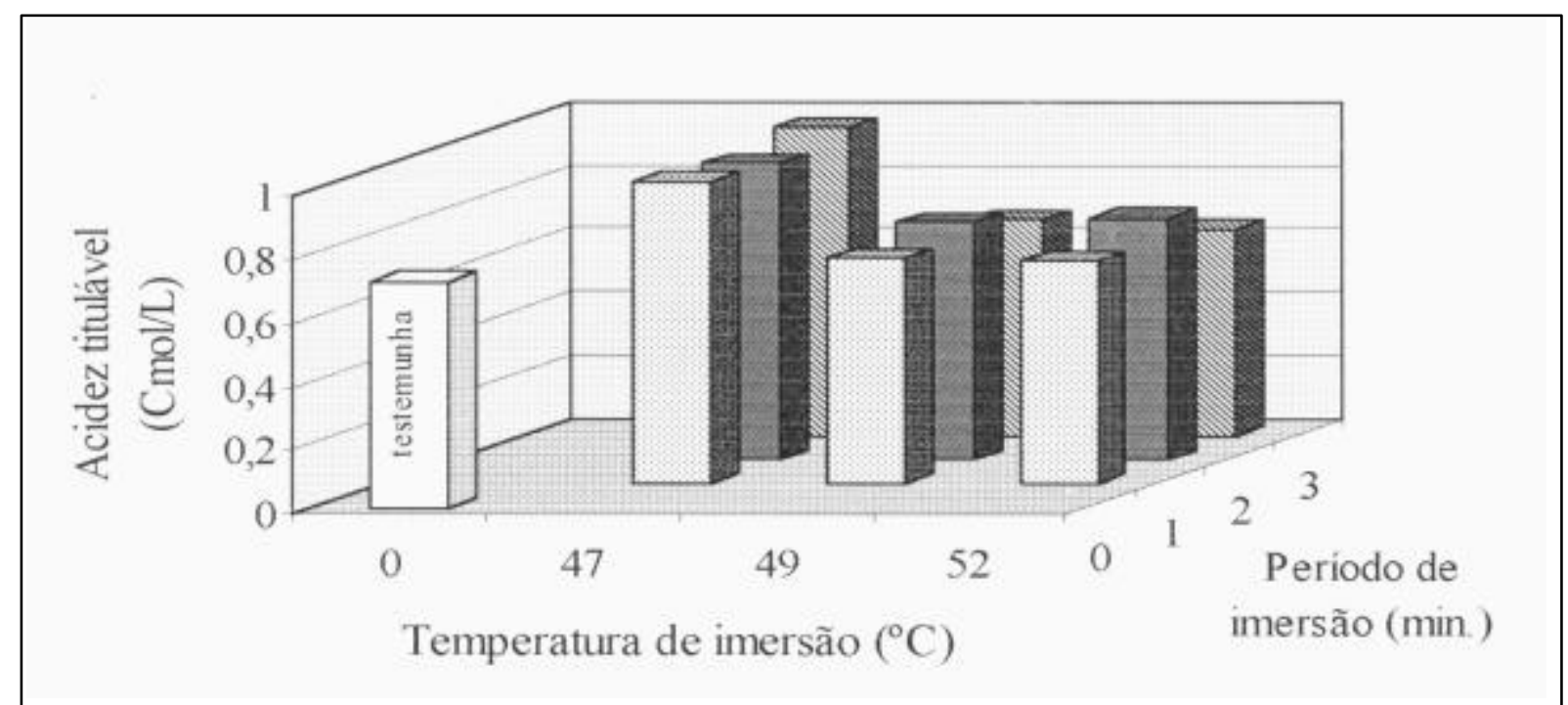

Figura 3 - Acidez titulável de maçãs cv. Fuji, inoculadas com Botryosphaeria dothidea, submetidas ao tratamento térmico com imersão em água quente, avaliadas após cinco meses em armazenamento refrigerado a $0^{\circ} \mathrm{C}$.

pronunciado de acordo com conclusões de HARDENBURG et al. (1986). Aumentando ainda mais a temperatura de tratamento, de $49^{\circ} \mathrm{C}$ para $52^{\circ} \mathrm{C}$, pode ter havido uma inativação de enzimas, a exemplo das conclusões de KLEIN \& LURIE (1990).

Os teores de acidez titulável foram significativamente diferentes entre os tratamentos apenas aos cinco meses em AR (Figura 3). Ocorreu o decréscimo da acidez na medida em que se aumentou a temperatura da água de tratamento, independentemente do período de exposição $\left(y=-0,045 x+3,02 ; r^{2}=0,67\right)$. Esta observação está de acordo com conclusões de KLEIN et al. (1990) e KLEIN \& LURIE (1990). Estes autores afirmam que o tratamento térmico reduz os teores de acidez titulável.

Para maçãs da cultivar Fuji, a manutenção de altos teores de acidez é uma característica importante, pois propicia melhor sabor em função do equilíbrio SST/acidez (BRACKMANN et al., 1998). Considerando-se o conjunto das três avaliações realizadas, constatou-se que não houve diferença estatística entre os frutos submetidos ao tratamento térmico e o tratamento testemunha.

Não foram constatadas diferenças significativas de peso em qualquer período de armazenagem das maçãs. Também não foram observados danos nos frutos que pudessem ser atribuídos aos tratamentos com água quente.

\section{CONCLUSÕES}

O tratamento térmico com imersão em água quente, dentro dos limites de temperatura e de tempo aplicados neste experimento, tende a aumentar os teores de sólidos solúveis totais em maçãs cv. Fuji, mantidas armazenadas por um, três e cinco meses em armazenamento refrigerado (AR). Além disso, há uma redução dos teores de acidez titulável com a elevação da temperatura da água de imersão, após cinco meses em ar refrigerado. As variáveis firmeza de polpa e perda de peso são pouco alteradas pelos tratamentos de imersão em água quente e tempos de armazenagem propostos.

\section{AGRADECIMENTOS}

À Empresa Mercochem, de Caxias do Sul, RS, e ao CNPq.

\section{REFERÊNCIAS BIBLIOGRÁFICAS}

BENDER, R.J. Manual da cultura da macieira. Florianópolis: EMPASC, 1986. Colheita e armazenagem: p.521-550.

BEN-SHALOM, N.; HANZON, J.; PINTO, R., et al. Cell wall changes and partial prevention of fruit softening in prestorage heat treated 'Anna' apples. Journal of the Science of Food and Agriculture, London, v.72, n.2, p.231-234, 1996.

BONETI, J.I. da S.; KATSURAYAMA, Y. Doenças da macieira. São Paulo : BASF, 1998. 85p.

BRACKMANN, A. Einfluß von Lagerung unter kontrollierter Atmosphäre (CA) und Äthylenebehandlungen auf verschiedene Merkmalen der Fruchtreife unter. besonderer Berücksichtigung der Aromabildung bei Äpfeln. Hohenheim, 1990. 115p. Tese (Doutorado em Ciências Agrárias) - Universidade de Hohenheim, Alemanha, 1990.

BRACKMANN, A.; BORTOLUZ, L.; BORTOLUZZI, G. Frigoconservação de maçã 'Fuji' em duas temperaturas e em atmosfera controlada. Revista Brasileira de Agrociência, Pelotas, v.4, n.1, p.26-30, 1998. 
CONWAY, W.S.; SAMS, C.E.; WANG, C.Y., et al. Additive effects of postharvest on reducing decay and maintaining quality in apples. Journal of the American Society for Horticultural Science, Alexandria, v.119, n.1, p.49-53, 1994.

CONWAY, W.S.; JANISIEWICZ, W.J.; KLEIN, J.D., et al Strategy for combining heat treatment, calcium infiltration, and biological control to reduce postharvest decay of 'Gala' apples. HortScience, Alexandria, v.34, n.4, p.700-704, 1999.

COUEY, H.M. Heat treatment for control of postharvest diseases and insect pests of fruits. HortScience, Alexandria, v.24, n.2, p.198-202, 1989.

D'HALLEWIN, G.; ARRAS, G.; CASTIA, T., et al. Reducing decay of Avana mandarin fruit by use of UV, heat and thiabendazole treatments. Acta Horticulturae, Wageningen, v.368, p.387-394, 1994

DHINGRA, O.D.; SINCLAIR, J.B. Basic plant pathology methods. 2 ed. Boca Raton : Lewis, 1995. 434p. Cap.5: Establishment of disease and testing for resistance.

HARDENBURG, R.E.; WATADA, A.E., WANG, C.Y. The commercial storage of fruits, vegetables and florist and nursery stocks. Washington: USDA, 1986. 136p. (Agriculture Handbook, 66).

KLEIN, J.D.; LURIE, S. Prestorage heat treatment as a means of improving poststorage quality of apples. Journal of the American Society for Horticultural Science, Alexandria, v.115, n.2, p.265-269, 1990
KLEIN, J.D.; CONWAY, W.S.; WHITAKER, B.D., $\boldsymbol{e} t$ al. Botrytis cinerea decay in apples is inhibited by postharvest heat and calcium treatments. Journal of the American Society for Horticultural Science, Alexandria, v.122, n.1, p.91-94, 1997.

KLEIN, J.D.; LURIE, S.; BEN-ARIE, R. Quality and cell wall components of 'Anna' and 'Granny Smith' apples treated with heat, calcium, and ethylene. Journal of the American Society for Horticultural Science, Alexandria, v.115, n.6, p.954-958, 1990.

LURIE, S.; FALLIK, E.; KLEIN, J.D., et al. Postharvest heat treatment of apples to control San Jose Scale (Quadraspidiotus perniciosus Comstock) and blue mold (Penicillium expansum Link) and maintain fruit firmness. Journal of the American Society for Horticultural Science, Alexandria, v.123, n.1, p.110-114, 1998.

LURIE, S., KLEIN, J.D. Calcium and heat treatments to improve storability of 'Anna' apples. HortScience, Alexandria, v.27, n.1, p.36-39, 1992.

NYANJAGE, M.O.; WAINWRIGHT, H., BISHOP, C.F.H. The effects of hot-water treatments in combination with cooling and/or storage on the physiology and disease of mango fruits (Mangifera indica Linn.). Journal of Horticultural Science \& Biotechnology, Ashford, v.73, n.5, p.589-597, 1998 